\title{
SUSCEPTIBILIDADE À HIPERTERMIA MALIGNA EM TRÊS PACIENTES COM SÍNDROME MALIGNA POR NEUROLÉPTICOS
}

\author{
HELGA C. A. SILVA*, VALÉRIA S. BAHIA**, ROGÉRIO A. A. OLIVEIRA*** \\ PAULO E. MARCHIORI****, MILBERTO SCAFF*****, ANA MARIA C. TSANACLIS ${ }^{* * * * * *}$
}

\begin{abstract}
RESUMO - A hipertermia maligna caracteriza-se por hipertermia, rigidez muscular, rabdomiólise, acidose e insuficiência de múltiplos órgãos. A hipertermia maligna anestésica decorre da exposição a halogenados e/ou relaxantes musculares despolarizantes. O método padrão para diagnosticar a suscetibilidade à hipertermia maligna é o teste da contratura muscular in vitro em resposta ao halotano e à cafeína. A síndrome maligna por neurolépticos caracteriza-se por hipertermia, síndrome extrapiramidal, acidose, instabilidade neurovegetativa e alterações neurológicas. Descrevemos três pacientes com síndrome maligna por neurolépticos e testes de contratura muscular positivos. Esse achado demonstra que ocasionalmente o músculo de pacientes com síndrome maligna por neurolépticos pode mostrar as alterações encontradas na hipertermia maligna anestésica.
\end{abstract}

PALAVRAS-CHAVE: doenças musculares, hipertermia maligna, síndrome maligna por neurolépticos.

\section{Malignant hyperthermia susceptibility in three patients with malignant neuroleptic syndrome}

ABSTRACT - Hyperthermia, skeletal muscle rigidity, rhabdomyolysis, acidosis and multiple system insufficiency characterize malignant hyperthermia. Anaesthetic malignant hyperthermia follows halogenated volatile agents and/or depolarizing muscle relaxants utilization. Diagnosis is based on in vitro muscle contracture in response to halothane and/or caffeine exposure. Neuroleptic malignant syndrome affects patients taking neuroleptic drugs; clinical findings include hyperthermia, extrapyramidal rigidity, acidosis, neurovegetative instability and neurological signs. We report three neuroleptic malignant syndrome patients with positive muscle contracture tests which shows that muscle from neuroleptic malignant syndrome patients may in some instances show alterations similar to those of anaesthetic malignant hyperthermia.

KEY WORDS: malignant hyperthermia, neuroleptic malignant syndrome, muscle disease.

A hipertermia maligna (HM) é síndrome clínica hipermetabólica e grave, que apresenta evolução rápida para o óbito e se caracteriza por hipertermia, rigidez muscular, rabdomiólise, acidose e insuficiência de múltiplos órgãos ${ }^{1}$. Na HM anestésica ocorre suscetibilidade geneticamente determinada à indução anestésica com halotano ou outros agentes voláteis hidrocarbonados e à exposição a relaxantes musculares despolarizantes, como a succinilcolina ${ }^{1,2}$. A incidência da HM anestésica varia, segundo a região, de 1 em 14000 até de 1 em 40000 anestesias ${ }^{1}$. Há seis genes que podem albergar mutações relacionadas à suscetibilidade à hipertermia maligna anestésica: MHS1 (cromossomo 19, gene do receptor rianodina), MHS2 (cromossomo 17, gene do canal de sódio do músculo esquelético adulto), MHS3 (cromossomo 7, gene da subunidade $\alpha 2 / \Delta$ do receptor di-

Departamento de Patologia: (*Doutora; *******Professora Associada) e Disciplina de Neurologia Clínica do Departamento de Neurologia (**Médica Preceptora, ***Médico Residente, ****Professor Associado, *****Professor Titular) da Faculdade de Medicina da Universidade de São Paulo (FMUSP), São Paulo - Brasil. Auxilio financeiro: FAPESP (96-2222-3, 95-9924-0). Aceite: 8-maio-2000.

Dra. Ana Maria C. Tsanaclis - Laboratório de Neuropatologia Experimental, Departamento de Patologia da FMUSP - Av. Dr. Arnaldo 455 sala 1121 - 01246-903. São Paulo SP - Brasil. 
hidropiridina), MHS4 (cromossomo 3, gene ainda não identificado), MHS5 (cromossomo 1, gene da subunidade $\alpha 1$ do receptor di-hidropiridina) e MHS6 (cromossomo 5, gene ainda não identificado) ${ }^{3}$. O diagnóstico genético é difícil devido ao grande número de mutações encontradas. Já foram descritas dezenove mutações ligadas ao gene do receptor rianodina segundo C. Müller em 1999 relatou no Annual Meeting of the European Malignant Hyperthermia Group, (Marseille, França). As mutações relacionadas aos seis genes citados correpondem a cerca de $50 \%$ das famílias pesquisadas; nas famílias restantes o gene envolvido ainda é desconhecido ${ }^{3}$.

O receptor rianodina é o canal de cálcio lento do retículo sarcoplasmático; quando há mutação, o receptor rianodina da fibra muscular esquelética apresenta aumento da sensibilidade aos agentes que estimulam a sua abertura, além de diminuição da resposta aos agentes que inibem o seu funcionamento ${ }^{4}$. A função alterada do receptor rianodina leva à liberação excessiva e contínua de cálcio, do retículo endoplasmático da fibra muscular para o citosol ${ }^{1}$. O excesso de cálcio intracelular inicia uma cascata de eventos bioquímicos que incluem desacoplamento da fosforilação oxidativa, com produção excessiva de calor e falência dos estoques de ATP; glicólise anaeróbia, com acidose láctica; interação actina-miosina, com contração muscular; dano à membrana celular e conseqüente morte da fibra muscular ${ }^{1,4}$. A ativação do metabolismo é evidente durante a crise de hipertermia maligna anestésica, mas provavelmente ocorre em menor grau durante toda a vida do paciente suscetível, acarretando alterações subclínicas da fisiologia e morfologia da fibra muscular esquelética ${ }^{4}$.

O teste-padrão para a determinação da presença de suscetibilidade à hipertermia maligna anestésica é, nos centros de pesquisa da Europa e América do Norte, o estudo da contratura do músculo esquelético in vitro em resposta ao halotano e à cafeína; há positividade a pelo menos uma dessas duas substâncias em praticamente $100 \%$ dos sobreviventes de um episódio de HM anestésica ${ }^{2,5}$. Estudos cooperativos mostraram que esse teste tem sensibilidade de $99 \%$ e especificidade de $93 \%$ quando se utiliza o protocolo europeu ${ }^{6}$. Nesse teste, um fragmento de biópsia muscular é conectado a um transdutor que afere o grau de contração muscular; o músculo é, então, exposto a dose única ou crescente de cafeína e/ou halotano ${ }^{7}$. A diferença entre a resposta do músculo de indivíduos normais e dos pacientes suscetíveis está no grau de contração alcançado e na sua sensibilidade às diferentes concentrações de cafeína e de halotano ${ }^{1,7}$.

A elevação da creatinofosfocinase sérica, encontrada em $50 \%$ dos familiares de pacientes com hipertermia maligna anestésica, não tem valor preditivo ${ }^{1}$. Outras técnicas não invasivas, como determinação da concentração de cálcio livre no citosol de linfócitos e espectroscopia com ressonância magnética para fósforo no músculo, apesar de promissoras, não podem ainda ser usadas para discriminar os suscetíveis na população geral ${ }^{4,8}$.

A síndrome maligna por neurolépticos (SMN) acomete 0,5 a $1 \%$ dos pacientes expostos ao uso de neurolépticos; o pico de incidência ocorre aos 40 anos e há predomínio do sexo masculino, na proporção de 2:1,9-12. A instalação do quadro clínico é lenta, desenvolvendo-se progressivamente hipertermia severa, alterações do nível de consciência, síndrome extrapiramidal, e alterações neurovegetativas (sialorréia, sudorese, taquicardia e instabilidade hemodinâmica), seguidas por rabdomiólise e acidose ${ }^{1}$. A mortalidade oscila entre 16 e $40 \%$ e o tratamento baseia-se no uso de agonistas dopaminérgicos ${ }^{1,10}$. Classicamente acreditava-se na existência de dois mecanismos básicos implicados na ocorrência da SMN: a administração de drogas que bloqueiam os receptores de dopamina no sistema nervoso central e a retirada de agonistas dopaminérgicos em pacientes com parkinsonismo idiopático ${ }^{10,12-15}$. Entretanto, essa visão tem sido questionada, em vista de vários fatos que sugerem a participação de mecanismos periféricos na ocorrência da síndrome, pelo menos em alguns dos casos de SMN. Entre esses fatos, pode-se citar 1) a semelhança entre o quadro clínico da SMN e da hipertermia maligna anestésica; 2) a ocorrência de rabdomiólise após anestesia em pacientes com história prévia de SMN; 3) a eficácia do dantrolene (bloqueador dos canais de cálcio da fibra muscular) no tratamento da SMN; 4) a positividade do teste de contratura muscular em alguns pacientes isolados com SMN; 5) e a associação entre SMN e doenças musculares, como a miopatia tipo central core e a síndrome de Satoyoshi ${ }^{13-14,16-21}$. Além disso, reforçando a hipótese de influência 
de mecanismos periféricos na SMN, Acharya e $\mathrm{RaO}^{22}$ e Lopez e Parra ${ }^{23}$ descreveram ação direta e dose-dependente da clorpromazina no músculo esquelético de rãs: baixas doses têm ação anticolinérgica, doses intermediárias potenciam contrações induzidas pela acetilcolina e doses elevadas provocam espasmos musculares.

Porém o estudo de grandes séries de pacientes com SMN não mostrou aumento da incidência de crises de hipertermia maligna anestésica nem mutações do gene do canal rianodina ${ }^{24,25}$. Da mesma forma, a realização sistemática do teste de contratura muscular in vitro mostra resultados normais na maioria dos pacientes ${ }^{15,26,27,28}$.

O presente artigo descreve três pacientes com antecedentes de SMN que tiveram resultados positivos no teste de contratura muscular em resposta ao halotano e à cafeína, demonstrando ser também suscetíveis à hipertermia maligna.

\section{MÉTODO}

\section{Pacientes}

Paciente 1 - 23 anos, feminina, branca. Paciente sem antecedentes patológicos, admitida com queixa de alteração do comportamento há dois dias, caracterizada por agitação psicomotora, discurso desconexo, idéias persecutórias, hiperfagia e insônia. Na admissão, apresentava-se pueril e confusa, com logorréia e ecolalia. Foi medicada com haloperidol $10 \mathrm{mg} / \mathrm{dia}$. No primeiro dia de tratamento apresentou distonia aguda, com disfagia, sendo associados o cloridrato de prometazina e o cloridrato de biperideno. No segundo dia, começou a cursar com febre contínua $\left(38^{\circ} \mathrm{C}\right)$. No $18^{\circ}$ dia, a paciente entrou em coma e apresentou pico de temperatura de $39,4^{\circ} \mathrm{C}$ e rigidez muscular generalizada. Os níveis séricos de creatinofosfocinase estavam aumentados(CPK - $324 \mathrm{Ui}$; normal até 90 Ui). A tomografia computadorizada de crânio (TC) e o líquido cefalorraquidiano (LCR) foram normais. Foi feito o diagnóstico de SMN, sendo suspenso o haloperidol e introduzidos levodopa (500 mg/dia), bromocriptina (7,5 mg/dia) e diazepam ( $40 \mathrm{mg} / \mathrm{dia})$. No primeiro dia de terapia houve regressão total da febre e rigidez muscular, com melhora do nível de consciência. O quadro psiquiátrico catatônico regrediu após 10 sessões de eletroconvulsoterapia. $\mathrm{O}$ transtorno bipolar maniforme foi tratado por um ano com carbolitium e clonazepam. A paciente foi reavaliada ao término do tratamento psiquiátrico; o exame físico geral não mostrava anormalidades, não havia deformidade músculo-esquelética ou qualquer alteração do exame neurológico. Não havia antecedente pessoal ou familiar de complicações anestésicas. Após dois anos a paciente foi submetida a biópsia muscular.

Paciente 2 - 23 anos, masculino, branco. Paciente sem antecedentes patológicos, internado com história de alteração do comportamento há um mês (insônia, alheamento, dificuldade de raciocínio, inquietação quanto à morte) e, há 15 dias, agressividade e alucinações visuais e auditivas. Após o início dos sintomas foi medicado em outro pronto-socorro com benzodiazepínicos e clorpromazina; três dias depois começou a apresentar febre contínua, hipertonia muscular difusa e crises convulsivas tônico-clônicas generalizadas. Na admissão, o paciente estava febril $\left(39^{\circ} \mathrm{C}\right)$, agressivo e confuso, com déficit de atenção, sinais de frontalização e rigidez muscular generalizada. Havia aumento dos níveis séricos de creatinofosfocinase (CPK - 4405 Ui; normal até 90 Ui). A TC mostrou edema cerebral difuso e extravasamento de contraste para o parênquima. O LCR mostrou hipercelularidade linfomonocitária (20 células); a proteinorraquia e a glicorraquia foram normais (30 e $60 \mathrm{mg} / 100 \mathrm{ml}$, respectivamente). O eletrencefalograma mostrou lentificação difusa da atividade elétrica cerebral, mais importante no hemisfério cerebral direito, além de ondas teta, sugerindo sofrimento cerebral difuso. Em vista desses dados, foi feita a suspeita diagnóstica de meningoencefalite viral, sendo iniciado aciclovir. Como não houve regressão do quadro, foi levantada a possibilidade de SMN e introduziu-se dantrolene $(10 \mathrm{mg} / \mathrm{kg} / \mathrm{dia})$ e bromocriptina (10 $\mathrm{mg} / \mathrm{dia}$ ). No segundo dia de terapia houve regressão total do quadro clínico. O paciente foi reavaliado após a alta hospitalar; o exame físico geral não mostrava anormalidades, não havia deformidade músculo-esquelética ou qualquer alteração do exame neurológico. Não havia antecedente pessoal ou familiar de complicações anestésicas. Após nove meses o paciente foi submetido a biópsia muscular.

Paciente 3 - 43 anos, masculino, mulato. Paciente sem antecedentes patológicos, admitido com história de traumatismo crânio-encefálico há 10 dias, após o que passou a apresentar cefaléia intensa. Antes da admissão foi medicado em outro pronto-socorro com clorpromazina e evoluiu com quadro progressivo de dores musculares generalizadas; dois dias antes da admissão, houve diminuição da diurese e surgimento de confusão mental. No momento da internação estava desorientado, com dor e rigidez muscular generalizadas, mais acentuadas nos membros inferiores. Os exames revelaram aumento dos níveis séricos de creatinofosfocinase (CPK $7550 \mathrm{Ui}$; normal até $90 \mathrm{Ui}$ ) e insuficiência renal (uréia $400 \mathrm{mg} \%$, creatinina $1,2 \mathrm{mg} \%$ ). A TC mostrou hemorragia meníngea 
perimesencefálica e silviana. A ultra-sonografia de membros inferiores foi compatível com síndrome de compartimentos. Foram feitos os diagnósticos de hemorragia meníngea pós-traumática e SMN, com insuficiência renal aguda associada à rabdomiólise. O paciente foi submetido a diálise peritoneal durante um mês, havendo regressão progressiva dos sintomas. Posteriormente, a ressonância magnética de encéfalo identificou múltiplos focos de gliose sequelar bifrontal e malformação de Chiari tipo I; a angiografia cerebral foi normal. O paciente foi reavaliado após receber alta hospitalar; o exame físico geral não mostrava anormalidades, não havia deformidade músculo-esquelética ou qualquer alteração do exame neurológico. Não havia antecedente pessoal ou familiar de complicações anestésicas. Após seis meses o paciente foi submetido a biópsia muscular.

\section{Métodos}

Em todos os três pacientes a biópsia muscular foi realizada sob raquianestesia, com sedação utilizando benzodiazepínicos ${ }^{29}$. Deve-se evitar a utilização de anestesia local quando a biópsia muscular tem por objetivo a pesquisa da suscetibilidade à hipertermia maligna; nesses casos o teste in vitro pode sofrer interferência do anestésico que se infiltra no músculo. A biópsia foi feita no músculo vasto lateral e dois dos fragmentos foram imediatamente colocados em solução de Krebs carbogenada e transportados para o laboratório. Esses fragmentos foram posteriormente dissecados e utilizados para o teste de contratura muscular in vitro em resposta ao halotano e cafeína, segundo metodologia do Grupo Europeu de Hipertermia Maligna ${ }^{7}$ O terceiro fragmento foi dividido em três partes e colocado em formol a $10 \%$, glutaraldeído a $2 \%$ e isopentano resfriado em nitrogênio líquido; esse material foi processado respectivamente para coloração de rotina (hematoxilina e eosina), microscopia eletrônica e colorações e reações histoquímicas (tricrômico de Gomori, ácido periódico de Schiff, Sudanblack B, ATPase 9.4, ATPase 4.3, Cox, NADH, SDH, AMP desaminase, alfa glicerofosfato-desidrogenase, fosfatase ácida e alcalina).

\section{RESULTADOS}

Paciente 1 - O teste de contratura muscular foi negativo em resposta ao halotano e positivo para a cafeína (contratura de $0,2 \mathrm{~g}$ a $2 \mathrm{mMol}$ ), sendo a paciente classificada como suscetível à hipertermia maligna. O estudo anatomopatológico do músculo revelou intensa variação de calibre das fibras musculares esqueléticas, com algumas fibras fendidas ou em necrose, além de aumento da média da área transversa de fibras tipo I.

Paciente 2 - O teste de contratura muscular foi positivo em resposta ao halotano (contraturas de $0,44 \mathrm{~g}$ a $1 \%$ e $0,3 \mathrm{~g}$ a $1 \%$ ) e negativo para a cafeína, sendo o paciente classificado como suscetível à hipertermia maligna. O estudo anatomopatológico evidenciou discreta variação de calibre, algumas fibras fendidas ou atróficas, aumento do colágeno endomisial, agrupamento de fibras tipo I, além de falhas nas reações oxidativas com aspecto de saca-bocados em fibras tipo I ("motheaten”). O estudo submicroscópico mostrou alteração das cristas mitocondriais, aumento e proliferação das tríades e acúmulo focal de lípides.

Paciente 3 - $\mathrm{O}$ teste de contratura muscular foi positivo em resposta ao halotano (contraturas de $0,52 \mathrm{~g}$ a $2 \%$ e $0,36 \mathrm{~g}$ a $1 \%$ ) e negativo para a cafeína, sendo o paciente classificado como suscetível à hipertermia maligna. O estudo anatomopatológico mostrou moderada variação de calibre, fibras fendidas ou em necrose, aumento da média da área transversa de fibras tipo I, falhas nas reações oxidativas com aspecto de saca-bocados em fibras tipo I ("moth-eaten"). O estudo submicroscópico mostrou acúmulo focal de lípides.

\section{DISCUSSÃO}

A SMN possui apresentação extremamente pleomórfica, que dificulta e retarda o diagnóstico e o tratamento, como demonstrado pela evolução dos três pacientes desse relato ${ }^{10}$. $\mathrm{O}$ diagnóstico de SMN foi mais difícil nos Pacientes 2 e 3, devido à coexistência de outros diagnósticos, no caso meningite viral e hemorragia meníngea, respectivamente. No Paciente 2, nem a meningite viral nem a SMN isoladamente justificam todas as alterações encontradas. Considerando esse paciente, por um lado, não houve melhora clínica após o uso de aciclovir; por outro lado, não há descrição de SMN com alterações do LCR, da TC e do eletrencefalograma, se bem que, teoricamente, essas alterações poderiam ser decorrentes das crises convulsivas. Os problemas no manejo da SMN não 
se limitam apenas ao diagnóstico clínico, pois sua fisiopatologia tem sido motivo de controvérsia ${ }^{13-}$ 15,18. Apesar da participação do sistema dopaminérgico central ser hoje indiscutível, ainda não se sabe o motivo pelo qual apenas alguns indivíduos apresentam a SMN, dentro do universo de pacientes que usam neurolépticos ou que interrompem o uso de dopaminérgicos. Os estudos realizados no músculo esquelético dos três pacientes desse relato revelaram alterações da fisiologia (teste de contratura muscular in vitro) e da morfologia (microscopia de luz e eletrônica), quando os pacientes não estavam em uso de neurolépticos e muito tempo após o episódio de rabdomiólise. É possível que esses pacientes sejam portadores de alterações do metabolismo muscular completamente subclínicas, mas que se tornam evidentes durante estímulos, como o uso clínico de neurolépticos ou testes in vitro com cafeína e/ou halotano.

O estudo da contratura do músculo esquelético in vitro em resposta ao halotano e à cafeína mostrou-se alterado nos três pacientes, mas cada paciente respondeu apenas a uma das drogas utilizadas (cafeína na Paciente 1 e halotano nos Pacientes 2 e 3). Esse teste, segundo o protocolo europeu, tem três padrões de resposta: ausência de contratura (MHN ou malignant hyperthermia negative), contratura em resposta às duas drogas, halotano e cafeína (MHS ou malignant hyperthermia susceptible) e contratura em resposta a apenas uma das drogas (MHE ou malignant hyperthermia equivocal) ${ }^{7}$. A resposta tipo MHE, encontrada no estudo do músculo dos três pacientes deste relato, é considerada do ponto de vista prático como positiva, mas esses pacientes podem ser portadores de outras alterações genéticas que não as classicamente relacionadas à HM e aguardam o progresso dos estudos genéticos para melhor classificação ${ }^{1,6}$. Acredita-se que o emprego de outras drogas, como rianodina e cloro-cresol, possa permitir classificar melhor os pacientes MHE e aumentar a especificidade do teste ${ }^{4}$. No momento, o teste de contratura muscular in vitro em resposta ao halotano e à cafeína é considerado o padrão para o diagnóstico da suscetibilidade à HM anestésica, mas como todo teste biológico tem limitações. No caso, os pontos de corte estabelecidos para separar os normais dos suscetíveis, quando da análise da contratura muscular, foram estabelecidos de forma a obter elevada sensibilidade $(99 \%)^{4,6}$. Assim, o risco de falso-negativos é mínimo, fato importante quando se trabalha com uma doença fatal como a HM. Por outro lado, a especificidade é menor (93\%), o que poderia dar margem a resultados falso-positivos ${ }^{6}$. Nesse sentido, alguns autores defendem que não há relação entre a HM anestésica e a SMN, e os relatos de testes de contratura positivos nessa população correspondem a falso-positivos ${ }^{15,26-28}$. Mas há outros grupos que atribuem a contratura anormal do músculo desses pacientes a defeitos musculares que os tornaram também mais propensos à $\mathrm{SMN}^{11,13,14,18}$.

O estudo anatomopatológico do músculo nos três pacientes com SMN deste relato mostrou algumas alterações que são consideradas inespecíficas tais como variação de calibre, necrose, fibras fendidas, fibras atróficas, aumento focal do conjuntivo endomisial, agrupamento e hipertrofia de fibras tipo I. Essas alterações poderiam ser explicadas como seqüelas do processo de rabdomiólise, ainda que a biópsia tenha sido feita com intervalo mínimo de seis meses. Por outro lado, todas essas alterações são também comumente descritas nas biópsias musculares dos pacientes com diagnóstico de HM anestésica, apesar de não permitirem caracterizar uma miopatia típica dessa doença $\mathrm{a}^{30,31}$. Entretanto, no músculo dos três pacientes do presente relato também foram encontradas alterações que sugerem miopatia, tais como o aspecto saca bocados nas reações oxidativas, alterações das cristas mitocondriais, acúmulo de lípides e aumento e proliferação das tríades. Essas alterações são freqüentemente encontradas no músculo esquelético na HM anestésica; apesar de isoladamente não permitirem fazer o diagnóstico da suscetibilidade à $\mathrm{HM}^{30,31}$. Silva ${ }^{32}$ mostrou que o aspecto saca bocados nas reações oxidativas, as alterações das cristas mitocondriais e o aumento e proliferação das tríades são significantemente mais freqüentes no grupo suscetível à HM.

As alterações encontradas no músculo esquelético dos pacientes do presente relato falam a favor de doença muscular de base favorecendo a ocorrência da SMN. A doença muscular de base desses três pacientes é a suscetibilidade à hipertermia maligna. A base fisiopatológica da crise de HM anestésica e das alterações morfológicas encontradas no músculo esquelético é o aumento crônico dos níveis intracelulares de cálcio ${ }^{4,33}$. MacLennan ${ }^{33}$ propõe que o excesso de cálcio leva a modificações 
das proteínas contráteis e estruturais, além de provocar exaustão energética decorrente de sobrecarga mitocondrial. Essa teoria explicaria as alterações morfológicas que geralmente são encontradas no músculo de $25 \%$ dos pacientes suscetíveis à HM anestésica ${ }^{30}$.

As alterações fenotípicas relacionadas às mutações da HM parecem ocupar um espectro que vai de resposta alterada a anestésicos até atrofia muscular, passando por um estágio intermediário de hipertrofia muscular ${ }^{1,433}$. Alguns pacientes apresentariam aumento da liberação de cálcio apenas quando da exposição a anestésicos desencadeadores ${ }^{4}$. Outros pacientes apresentariam aumento espontâneo da liberação de cálcio, de tal forma que ocorreria hipertrofia muscular se o sistema regulatório conseguisse compensar o excesso de cálcio no citoplasma; caso contrário, ocorreria atrofia e morte da fibra muscular ${ }^{33}$.

A HM é uma síndrome resultante de elevação dos níveis intracelulares de cálcio; não é uma única doença, pois a mutação do gene rianodina é apenas uma entre outras causas possíveis ${ }^{1}$. Da mesma forma, o teste de contratura muscular é um marcador dessa anormalidade do metabolismo do cálcio intracelular, não significando que o paciente tem ou não determinada mutação ${ }^{4,6}$. Por outro lado, o teste de contratura muscular positivo significa que existe uma anormalidade do funcionamento da fibra muscular que pode levar, com o tempo, a alterações da morfologia da fibra muscular ou até a uma miopatia clinicamente evidente ${ }^{33}$.

Certamente, a SMN e a HM são doenças diferentes. Entretanto, parece haver um subgrupo de pacientes com SMN que possui doenças musculares de base que podem predispor às duas síndromes ${ }^{16,17}$. Nesse sentido, em 1999 foi descrita pela primeira vez a ocorrência da SMN em um paciente que havia sobrevivido a uma crise de HM anestésica ${ }^{34}$. Dessa forma, pacientes com SMN deveriam ser encaminhados para realização de investigação diagnóstica da sua suscetibilidade à HMA e de doenças musculares subclínicas ${ }^{17,35}$.

Agradecimento - Agradecemos à Sra. Anna Mary Zenker Brandão pela realização das colorações e reações histoquímicas.

\section{BIBLIOGRAFIA}

1. Kozak-Reiss G, Coursange F, Aubert M. Hyperthermies malignes. In Encyclopedie Medico-chirurgicale. Techniques Chirurgicales. Anesthésie - Reanimation Paris: Ed. Techniques, 1991:1-18.

2. Tein I, DiMauro S, Rowland LP. Myoglobinuria . In: Rowland LP, DiMauro S (eds). Handbook of clinical neurology, myopathies. Amsterdan: Elsevier, 1992:553-574.

3. Lunardi J. Genetic investigation of a rare disease: malignant hyperthermia. In Tegazzin V, Pintore G, Vincenti E (eds). Anestesia e malatie neuromuscolari. Torino: Minerva Medica, 1998:140-143.

4. Loke J, MacLennan DH. Malignant hyperthermia and central core disease: disorders of Ca 2+ release channels. Am J Med 1998;104:470-486.

5. Hopkins PM, Halsall PJ, Ellis FR. Diagnosing malignant hyperthermia susceptibility. Anaesthesia 1994;49:373-375.

6. Loke JCP, MacLennan DH. Bayesian modeling of muscle biopsy contracture testing for malignant hyperthermia susceptibility. Anesthesiology 1998;88:589-600.

7. Ellis FR, Halsall PJ, Ording H, et al. A protocol for the investigation of malignant hyperpyrexia (MH) susceptibility. Br J Anaesth 1984;56:1267-1269.

8. Bendahan D, Kozak-Ribbens G, Rodet L, Confort-Gouny S, Cozzone PJ. 31Phosphorus magnetic resonance spectroscopy characterization of muscular metabolic anomalies on patients with malignant hyperthermia. Anesthesiology 1998;88:96-107.

9. Bertorini TE. Myoglobinuria, malignant hyperthermia, neuroleptic malignant syndrome and serotonin syndrome. Neurol Clin 1997;15:649-671.

10. Granner MA, Wooten GF. Neuroleptic malignant syndrome or parkinsonism hyperpirexia syndrome. Semin Neurol 1991;11:228-235.

11. Heiman-Patterson T.D. Neuroleptic malignant syndrome and malignant hyperthermia. Med Clin N Am 1993;77:477-492.

12. Toru M, Matsuda O, Makiguchi K, Sugano K. Neuroleptic malignant syndrome-like state following a withdrawal of antiparkinsonian drugs. J Nerv Ment Dis 1981;169:324-327

13. Caroff S, Rosenberg H. Neuroleptic malignant syndrome and malignant hyperthermia. J Clin Psychopharmacol 1983;3:120-121.

14. Downey GP, Rosenberg M, Caroff S et al. Neuroleptic malignant syndrome. Am J Med 1984;77:338-340.

15. Krivosic-Horber R, Adnet P, Guevart E, Theunynck D, Lestavel P. Neuroleptic malignant syndrome and malignant hyperthermia. Br J Anaesth 1987;59:1554-1556.

16. Adachi H, Riku S, Fujishiro K, Kuru S. A case of Satoyoshi syndrome with symptons resembling neuroleptic malignant syndrome. Rinsho Shinkeigaku 1998;38:637-640. 
17. Calore EE, Cavaliere MJ, Perez NM, Russo DH, Wakamatsu A, Razzouk D. Hyperthermic reaction to haloperidol with rigidity, associated to central core disease. Acta Neurol 1994;16:157-161.

18. Caroff SN, Rosenberg H, Fletcher JE, Heiman-Patterson TD, Mann SC. Malignant hyperthermia susceptibility in neuroleptic malignant syndrome. Anesthesiology 1987;67:20-25.

19. Kelly D, Brull SJ. Neuroleptic malignant syndrome and mivacurium: a safe alternative to succinylcholine? Can J Anaesth 1994;41:845-849.

20. May DC, Morris SW, Stewart RM, Fenton BJ, Gaffney FA. Neuroleptic malignant syndrome: response to dantrolene sodium. Ann Intern Med 1983;98:183-184.

21. Weinberg S, Twersky RS. Neuroleptic malignant syndrome. Anesth Analg 1983;62:848-850.

22. Acharya SRK, Rao ARG. The action of chlorpromazine on the skeletal muscle of frog. Curr Sci 1975;44:147-149.

23. Lopez JR, Parra L. Effects of chlorpromazine on $\left\{\mathrm{Ca}^{2+}\right\}$ in skeletal muscle. (Abstr). Can J Anaesth 1989;36:S147-148.

24. Hermesh H, Aizenberg D, Lapidot M, Munitz H. Risk of malignant hyperthermia among patients with neuroleptic malignant syndrome and their families. Am J Psychiatry 1988;145:1431-1434.

25. Miyatake R, Iwahashi K, Matsushita M, Nakamura K, Suwaki H. No association between the neuroleptic malignant syndrome and mutations in the RYR1 gene associated malignant hyperthermia. J Neurol Sci 1996;143:161-165.

26. Adnet P, Krivosic-Horber R, Reyford H, Leys D, Adamantidis M, Dupuis B. Le syndrome malin des neuroleptiques et l'hyperthermie maligne anesthésique ont-ils un mécanisme commun? Presse Med 1990;19:1460.

27. Adnet PJ, Krivosic-Horber RM, Adamantidis MM, et al. The association between the neuroleptic malignant syndrome and malignant hyperthermia. Acta Anaesthesiol Scand 1989;33:676-680.

28. Bello N, Adnet $\mathrm{P}$, Saulnier F, et al. Absence de sensibilité à l'hyperthermie maligne peranesthésique chez 32 patients ayant développé un syndrome malin des neuroleptiques. Ann Fr Anesth Réanim 1994;13:663-668.

29. Mauritz W, Hackl W, Winkler M, Sporn P, Steinbereithner, K. Anesthesia in malignant hyperthermia susceptible patients. Acta Anaesthesiol Belg 1990;41:87-94.

30. Figarella-Branger D, Kozak-Ribbens GK; Rodet L. Pathological findings in 165 patients explored for malignant hyperthermia susceptibility. Neuromuscul Disord 1993;3:553-556.

31. Harriman DGF. The pathology of malignant hypertermia. In: Mastaglia FL, Detchant LW (eds). Skeletal muscle pathology. 2Ed. Tokyo: Churchill Livingstone, 1992:541-562.

32. Silva HCA. Hipertermia maligna: positividade do teste de contratura muscular in vitro e alterações neuromusculares associadas. Tese Faculdade de Medicina da Universidade de São Paulo. São Paulo: 1999.

33. MacLennan DH. The role of skeletal muscle ryanodine receptor. Soc Gen Physiol Ser 1995;50:89-100.

34. Portel L, Hilbert G, Gruson D, Favier J-C, Gbikpi-Benissan G, Cardinaud J-P. Malignant hyperthermia and neuroleptic malignant syndrome in a patient during treatment for acute asthma. Acta Anaesthesiol Scand 1999;43:107-110.

35. Merry SN, Merry AF. Neuroleptic malignant syndrome and malignant hyperthermia.[Letter] N Z Med J 1988;101:431. 